\title{
The Environmental Performance of Traction Batteries for Electric Vehicles from a Life Cycle Perspective
}

\author{
Giulia SANDRINI ${ }^{1 *}$, Beatrice CÓ $^{2}$, Giuseppe TOMASONI ${ }^{3}$, Marco GADOLA $^{4}$, \\ Daniel CHINDAMO 5
}

${ }^{1-5}$ Department of Mechanical and Industrial Engineering, University of Brescia, I-25123 Brescia, Italy

\begin{abstract}
The aim of this review article is the analysis of the results obtained from the scientific literature concerning all the phases that make up the life cycle of traction batteries for electric vehicles, in order to evaluate the associated environmental impact. In this regard, some scientific articles dealing with LCA studies concerning electric vehicles, with particular reference to batteries, will be examined. The revision of these articles will provide a general framework for the production, use and recycling phases of traction batteries. In particular, different parameters that influence the outcome of the LCA studies will be shown, parameters on which we can then act to improve the environmental impacts of the transition from internal combustion vehicles to electric mobility. These parameters are represented by the chemistry of the battery considered, aspect at the centre of the discussion, by the specific energy and efficiency of the battery pack, by the durability of the latter, but also by other aspects, such as the energy mix considered (both for the production phase, for the use phase and for recharging) and the functional unit chosen for the study, which determines a different approach, related to the analysis of a specific problem or aspect rather than another. Finally, the usefulness of the recycling practice and the related problems will be shown. In fact, the recycling must be perfected according to the battery chemistry in question to obtain benefits and better reduce environmental loads.
\end{abstract}

Keywords - Automotive; electric mobility; electric vehicles; global warming; green mobility; LCA (Life Cycle Assessment); lithium batteries; resource depletion; sustainability

\begin{tabular}{|ll}
\hline \multicolumn{2}{l}{ Nomenclature } \\
$A P$ & Acidification Potential \\
$B E V$ & Battery Electric Vehicle \\
$B M S$ & Battery Management System \\
$\mathrm{CO}_{2}$ & Carbon dioxide \\
$F D P$ & Fossil Depletion Potential \\
FEP & Freshwater Eutrophication Potential \\
FETP & Freshwater Ecotoxicity Potential \\
GWP & Global Warming Potential \\
HTP & Human Toxicity Potential \\
\hline
\end{tabular}

*Corresponding author.

E-mail address: g.sandrini005@unibs.it 


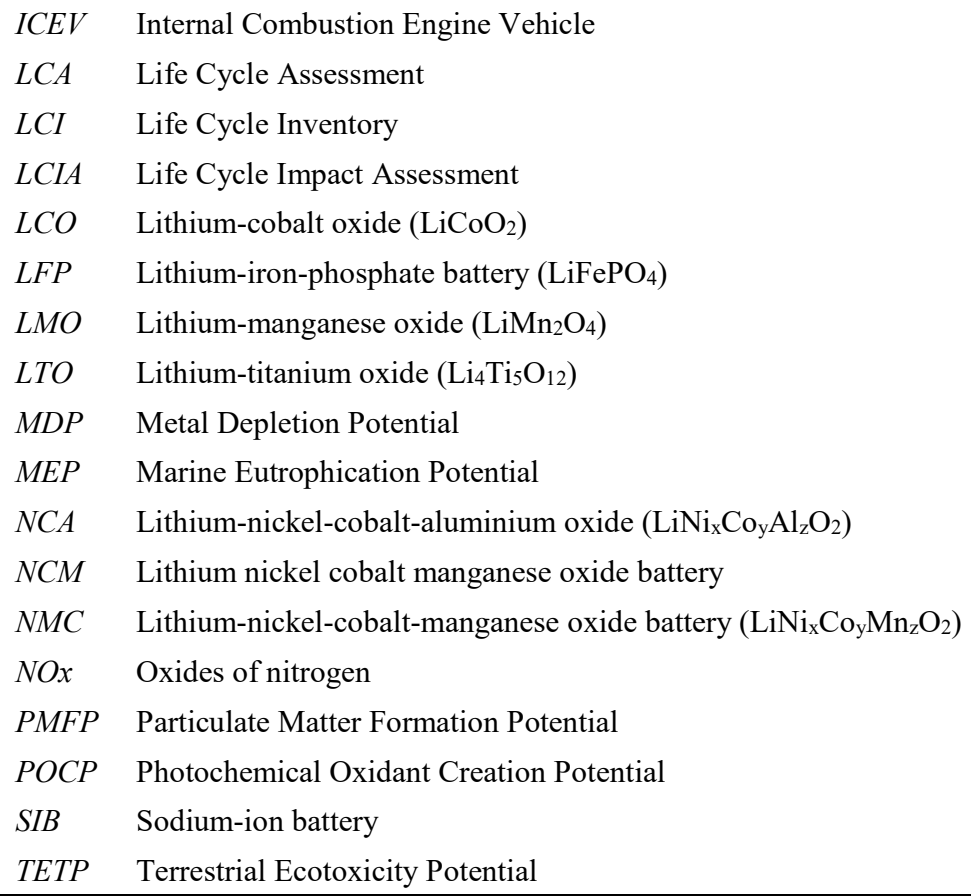

\section{INTRODUCTION}

Environmental problems and the depletion of fossil resources have led to consider the use of renewable energies. To exploit this type of energy, accumulation systems are required that store the energy and make it available when necessary; for vehicles traction, to date, batteries are among the best candidates for this purpose [1].

This work mainly focuses on the contribution of the various battery chemistry types with regard to the environmental impact. The battery pack, in fact, is the component that has the greatest impact on the environment as regards the transition from internal combustion vehicles to electrified vehicles.

Thanks to the analysis of the articles in the literature, information relating to the life cycle associated mainly with traction batteries for electric vehicles was collected and reorganized.

Although lead-acid batteries are still adopted on some electric road vehicles [2] the most widespread technology for the moment is (and will be, at least in the short term) the lithiumion batteries (LIBs) [1]. These, in fact, compared to other commonly used batteries (leadacid, nickel cadmium, metal hydrides) have a higher energy density and higher power density, a long life cycle, a strong environmental adaptability and a low level of self-discharge.

Types of commercial lithium-ion batteries are lithium-cobalt oxide $\left(\mathrm{LiCoO}_{2} ; \mathrm{LCO}\right)$, lithium-iron-phosphate $\left(\mathrm{LiFePO}_{4} ; \mathrm{LFP}\right)$, lithium-manganese oxide $\left(\mathrm{LiMn}_{2} \mathrm{O}_{4} ; \mathrm{LMO}\right)$, lithiumnickel-cobalt-manganese oxide ( $\left.\mathrm{LiNixCoyMnz} \mathrm{O}_{2} ; \mathrm{NMC}\right)$, lithium-nickel-cobalt-aluminium oxide ( $\left.\mathrm{LiNi}_{\mathrm{x}} \mathrm{CoyAlzO}_{2} ; \mathrm{NCA}\right)$ and lithium-titanium oxide $\left(\mathrm{Li}_{4} \mathrm{Ti}_{5} \mathrm{O}_{12} ; \mathrm{LTO}\right)$, which has lithium titanate as an anode.

All these batteries could be used in electric vehicles because they are able to provide the necessary performance in automotive applications and, based on their characteristics, different results are obtained: LMOs have a high specific power; NCAs and NMCs are the 
cheapest, thermally stable and highest specific energy lithium-ion batteries; LFPs have a fairly flat open circuit voltage curve, but have low capacity and a high self-discharge rate; LTOs, on the other hand, have a long duration and fast recharge, but a low specific energy and a higher cost [3].

It is also important to remember that, for automotive applications, the battery pack is no longer deemed usable when it has an effective capacity approximately $80 \%$ less than its nominal capacity [4].

The interest in electric vehicles arises mainly from the fact that their motor does not emit atmospheric pollutants directly into the environment during the use phase. On the other hand, however, some emissions are necessarily produced during the production phase of the electric powertrain and during the vehicle use phase, due to the production of the electricity required to recharge the batteries. Therefore, it is necessary to investigate whether this effect goes to counterbalance the benefits that can be obtained during the use phase of the electric vehicle or even to aggravate the general result [5].

This article analyses the different stages that make up the battery life cycle: extraction and production, use and, finally, recycling. In this way, we will try to highlight, for each phase of the life cycle, the factors that act as a brake in the change towards electric mobility and the improvements that can help in this step, in order to actually obtain an overall benefit, presenting in short also the new emerging technologies born to achieve this goal.

It is not only the climate change aspect that will be addressed, although it is the issue most often discussed in such studies and especially most prevalent in common thinking, since a change in impact in terms of climate change may be accompanied by a change in environmental impact in other impact categories. For this reason, studies on the subject have been chosen in such a way as to achieve wide viewing angle, whereas many of the possible impact categories.

Today's research focuses on storage systems suitable for electric mobility, being the low battery range that most hinders the affirmation of electric vehicles on the market. The motivation that drives us to reconsider electric vehicles relates to the increasingly growing concerns about the environment, especially inherent to the phenomenon of global warming. The greenhouse gas most responsible for global warming is carbon dioxide. The source of carbon dioxide emissions is connected to the transport sector for an amount equal to $32 \%$, estimated in the period from 1980 to 1999 [6]. This percentage is however destined to increase in the event that they are not implemented measures that mitigate the amount of emissions released into the environment, since the transport sector is on the rise, particularly due to the growing number of developing countries, including Asia Pacific which represents a large share of the world population.

An EU-imposed target would therefore be to reduce transport-related emissions by $60 \%$ of 1990 levels by 2030 [7]. Furthermore, it is interesting to mention the law of 16 January 2019 (formal adoption on 3 April 2019) [8], [9], as the European Parliament voted for the further reduction of carbon dioxide $\left(\mathrm{CO}_{2}\right)$ emissions for the newly registered vehicles. In particular, cars and light commercial vehicles (vans) registered from 2025 will have to emit $15 \%$ less $\mathrm{CO}_{2}$ and by 2030 cars will have to emit $37.5 \%$ less $\mathrm{CO}_{2}$, while light commercial vehicles will have to emit $31 \%$ less. These regulations were approved during the plenary session on 27 March 2019 and on 18 April of the same year the proposal was also launched to cut $\mathrm{CO}_{2}$ emissions from new trucks by $30 \%$ compared to 2019 levels, by 2030 [10].

The problem associated with internal combustion vehicles is not only that of global warming, but it is also connected with the emissions of other pollutants associated with the combustion process while driving, such as unburned products and $\mathrm{NO}_{\mathrm{x}}$. Furthermore, the 
problem is also associated with the non-infinite availability of fossil fuels [6], [11] and noise pollution.

In fact, in most European countries, it is estimated that over $50 \%$ of the population is constantly exposed to noise exceeding $55 \mathrm{~dB}$ intensity, levels which, according to the World Health Organization, can cause serious harm to human health. The World Health Organization has recommended to stay below certain noise levels, which were within the targets set for 2020 but have not been achieved [12]. On the other hand, noise pollution is expected to increase due to the increasing mobility of people, this problem is partly resolvable thanks to electric mobility, but not entirely since an important source of noise comes from tires.

\section{MAterials AND MethodS}

The literature analysis was focused on articles that deal with studies conducted using the LCA (Life Cycle Assessment) methodology. LCA is often used in the automotive field in order to assess benefits and drawbacks of a specific technology, as in [13]. In this case various studies concerning traction batteries for electric vehicles were considered and compared.

The main objective of this literature review is to provide an overview of the batteries used for traction of electric vehicles, with the ultimate aim of identifying which are the most demanding phases from an environmental point of view and how these can be addressed in order to limit their impact.

\subsection{Life Cycle Assessment (LCA)}

The Life cycle assessment or LCA is an internationally standardized methodology for assessing environmental impacts associated with all the stages of the life cycle of a commercial product, process, or service. According to ISO 14040, the LCA structure consists of four main steps (Fig. 1) [14], listed below.

1. Goal and Scope Definition: this is the preliminary phase of the study, in which the purposes, the functional unit, the boundaries of the system studied, the reference scenario, the assumptions and limits are defined.

2. Life Cycle Inventory (LCI): it is the phase dedicated to the analysis of energy and material flows (inputs and outputs) associated with the life cycle of the process or activity in question.

3. Life Cycle Impact Assessment (LCIA): it is the study of the environmental impact that the transport and use of resources cause in the various production processes analysed in the Inventory.

4. Life Cycle Interpretation: is the final part of the study, which aims to propose the necessary changes in processes and production activities. They must be evaluated iteratively through the LCA itself and possibly in parallel with studies of sensitivity and propagation of uncertainty. 


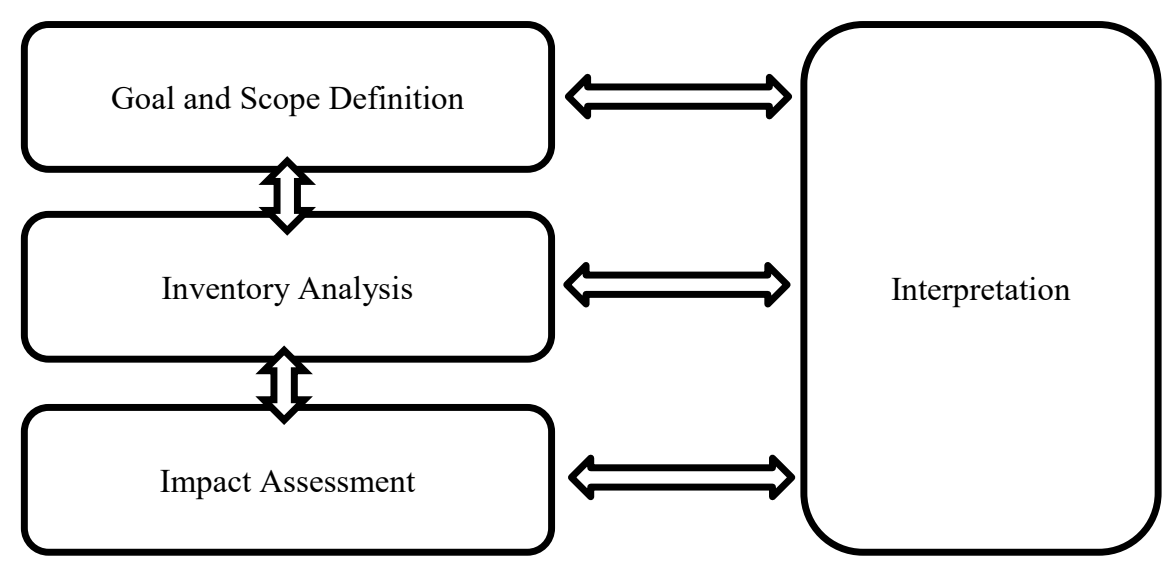

Fig. 1. Life Cycle Assessment (LCA) framework defined by ISO 14040.

\subsection{Search Engine}

The search for significant articles in the literature was carried out mainly through the 'Scopus' search engine and, secondarily, through 'ResearchGate' and 'ScienceDirect'.

\subsection{Selection of Articles}

The research of the articles began with the aim of understanding how traction batteries for electric vehicles were addressed in the literature in LCA studies and which variables could influence the results. In this way, the different phases of the life cycle and the various thematics were researched in a targeted way when the need to expand some aspects emerged. Each topic was then explored by searching for specific keywords in the title and abstract of the articles, using the search engines mentioned in the previous section.

The research was further enriched through articles cited in the bibliography of some authors (of initially selected articles). The work was then completed by taking into consideration the results and comments of other studies (reported in the references in the form of bibliography and sitography) in order to have a picture as complete as possible of the topic dealt with.

The research then led to the analysis of 18 articles, which are the focus of the literature review of this article. It was considered that these articles were sufficient to describe the main issues related to electric vehicles, in particular as regards the environmental impacts of the different phases of the battery life cycle.

Article [15] deals with a specific chemistry, namely nickel-cobalt-manganese oxide (NCM), which is one of the most used due to its high specific density. This article offers an overview of the issues related to the production phase, especially the preparation phase of the cell materials, and the benefits associated with the recycling practice.

The article [16] analyses various types of recycling processes and different battery chemistries. Articles [17]-[19] deal with innovative technologies for the batteries production, in particular article [19] deals with the SIB battery. The article [20] instead compares different production technologies. Articles [21] and [22] address the issue of resource depletion. Articles [23] and [24] deal with the issue of recycling. Article [25] instead presents the second life of batteries in applications other than those for which these batteries were produced (for traction). Articles [26] and [27] have been considered thanks to the bibliographic citations of some authors analysed. In particular, these articles deal with the aspect concerning the energy mix used for the production phase and, furthermore, article [27] also considers the mix for 
the use phase. Article [28] describes the different energy mix expected up to 2050. In article [11] a comparison is made between an internal combustion engine vehicle and an electric car for the Lithuanian case. The analysis of this study revealed a contrasting result compared to a similar study conducted in Italy and presented in the article [29]. [30] is a very comprehensive article concerning the operation mode. Finally, article [31] deals with LFP chemistry, mentioned in several articles and indicated as an alternative to NCM.

\section{Results}

In the next sections the selected articles will be analysed. In particular, the different impact categories considered will be statistically characterized and the information contained in the articles will then be used to represent a general picture of the life cycle of traction batteries for electric vehicles, considering all the main phases of the cycle (cradle-to-grave approach): extraction and production, use and finally recycling.

\subsection{Impact Categories}

Most of the studies considered deal with the impact category relating to climate change $(94.4 \%)$. The impact category relating to resource depletion also appears in several articles, in about $83.3 \%$, and this reflects the growing concern related to the exploitation of fossil fuels for the ICEV and minerals for the electric ones. $66.7 \%$ of the studies considered risks related to human health as an impact category. The impact categories relating to the ecosystem range from $50 \%$ to $55 \%$, due to the concern to safeguard both biotic and abiotic factors. The other impact categories are, on the other hand, less considered in scientific studies in the literature. Fig. 2 shows a bar graph showing the incidence of the impact categories considered in the 18 selected articles.

Many LCA studies report only the impact categories for which reliable and comprehensive data exist. In fact, the dynamics of the effects induced by certain substances are not yet particularly known and, moreover, often lead to different impact phenomena, giving rise to cascade effects that are difficult to evaluate [32].

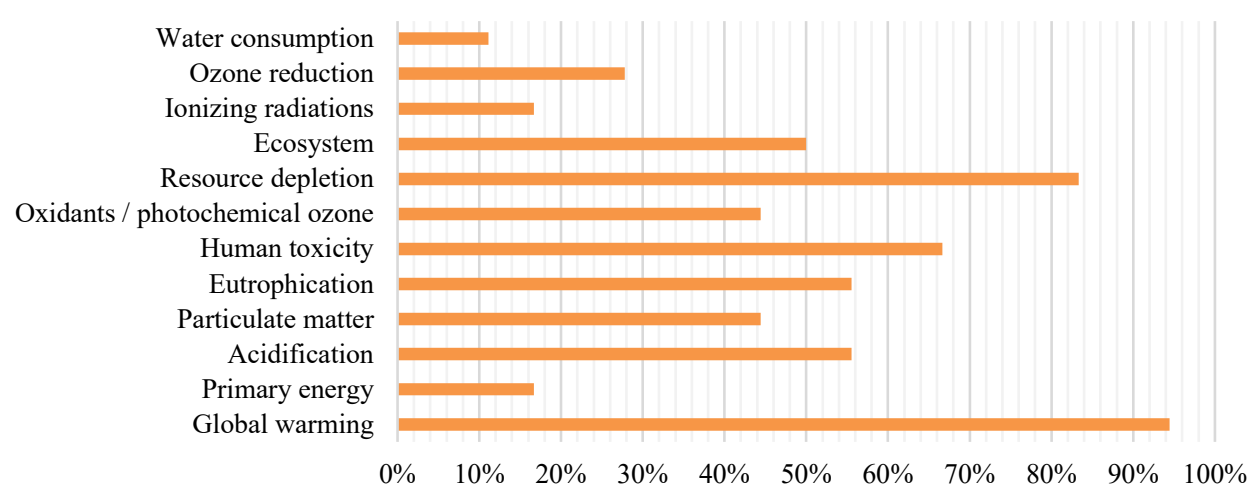

Fig. 2. Graphical representation of the percentage of incidence of the impact categories considered by the studies analysed in this article. 


\subsection{Extraction and Production Phases}

The article [29] shows the comparison between an internal combustion vehicle and an electric vehicle, both based on the virtual model of the reference car of the ALLIANCE project [33], namely the SuperLightCar. The article [11] compares the Fiat TIPO ICEV powered by two different fuels, diesel and petrol, and the Nissan Leaf ACENTA electric vehicle, all vehicles of the year 2008 .

In the results obtained from the two studies there is agreement in affirming the presence of a greater share of impact in the categories relating to human toxicity and the exhaustion of resources, in particular of metals, for the electric vehicle compared to the thermal one.

The results obtained in relation to human toxicity are also confirmed in other more recent studies conducted by other authors and they are mainly related to the production phase [11], [29].

Human toxicity is mainly related to the processing of chemical substances and metals, necessary for the manufacture of batteries and electric motors, and to the mining activities necessary for the extraction of raw materials, which are used in the production phases of batteries [22], [29].

Furthermore, the metal supply chain, in addition to determining exhaustion of the metals themselves, is the main cause of particulate emissions [22], [29]. The creation of atmospheric particulate is also linked to the energy required for production if it is mainly based on the use of solid sources [22]. The contribution of the energy mix used is therefore important.

For these reasons, the battery is the key element in determining the spread of electric vehicles.

In particular, it is the materials used for the production of batteries and their processing that cause a preponderant impact on human toxicity, on the exhaustion of metals, but also on other impact categories. Everything is therefore influenced by the chemistry of the battery in question, i.e., by the type of materials used and by their processing technology.

From the study of the article [15] it would seem that the greatest contribution to the environmental impact is mainly attributable to the preliminary phase of preparation and processing of the materials necessary for the manufacture of the cells components, compared to the production phase of the battery pack (Fig. 3).

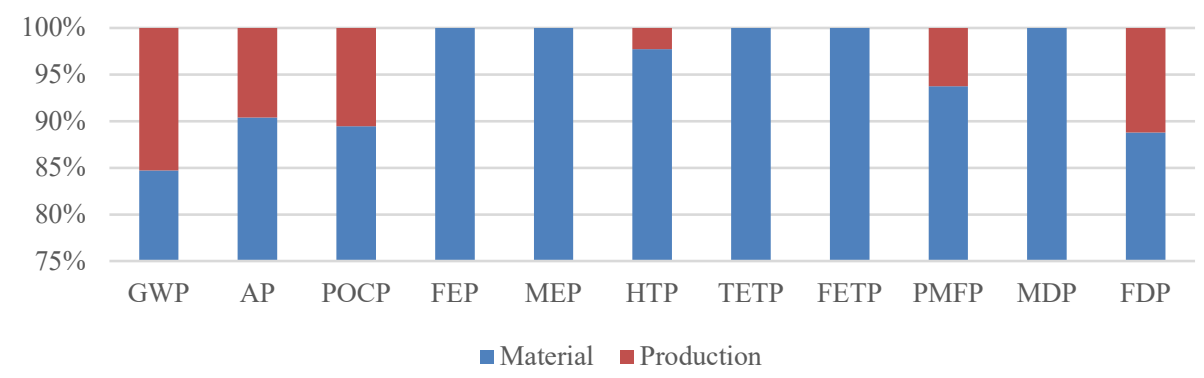

Fig. 3. Results obtained from the analysis of the life cycle of the $1 \mathrm{kWh}$ of the NCM battery, in the impact categories according to the V1.11/World ReCiPe H method [15].

Chemicals that include cobalt in the cathode structure determine a greater share of metal depletion, since it is defined as a critical element [16] and worsens its position if adequate measures are not applied to reduce its use [34]. The criticality of cobalt is confirmed by all five methodologies used for the assessment of environmental impacts in the study [21]. 
What was said for cobalt, it can also be said for nickel, which has a greater impact on resource depletion for NCM and NCA chemicals than LFP and SIB in the study [16] and the same is true for NiMH compared to LFP and NCM in the study [31]. Nickel is also indicated as critical in the study [21] for all five methodologies used and, in the form of nickel sulphate, it is considered to be, in the study [26], the second material to cause metal depletion for the cathode.

Copper is also defined as a critical element and its presence in the anodic collector involves a high consumption of resources and this is stated in several studies (for example in the studies [16], [21] and [26]).

Despite this, according to the study [34], the copper supply chain would not cause problems in the diffusion of low-carbon technologies (electric vehicles, photovoltaic and wind sector) until the period considered, i.e., 2030.

According to articles [17] and [26], manganese is a heavy metal that would cause significant resource depletion for the cathode of the NCM battery. In the study [22], manganese is the main reason for the difference in impact in the metal depletion category between LMO and LFP batteries, LFP being manganese-free. Despite this, according to the study [34], a significant increase in manganese demand is not expected by 2030 .

The different importance attributed to manganese could be explained by the study [21], which states that the ReCiPe method of assessing environmental impacts, used by studies [17], [22] and [26], is not adequate to evaluate the effective availability of resources, since it is based on the additional economic effort required by future generations to extract a resource that is abundant today, which will reduce its concentration as a result of today's exploitation. The same problem would also be present for the EcoIndicator99 method, which uses the same approach, but considering the additional energy instead of the additional cost. As for manganese, these methods lead to conflicting results also for aluminium [21]. Therefore, the results indicating a criticality for manganese and aluminium seem to be questionable.

The article [21] highlights the need to also take into account other essential materials for the electric powertrain, not used directly in the battery, used for example for the BMS and, in general, for battery electronics.

Essential materials for the production of lithium-ion batteries are lithium itself and graphite. An increase in the demand for lithium and graphite is expected [34], in particular by $2898 \%$ and $524 \%$ respectively by 2030 compared to today, in order to convert the entire current mobility into electric [35]. However, there is no certainty in stating whether lithium is indeed a critical element, as there are uncertainties about the extent of its reserves worldwide [34]. Furthermore, methodologies such as ReCiPe and EcoIndicator99 do not include the evaluation of this element in the resource depletion and therefore the criticality associated with its supply is underestimated [21], [26], [31].

Article [26] deals with an LCA analysis relating to the production of the NCM battery. The results of this LCA study show that the main responsible for most of the scores achieved on the various impact categories considered by the study are the manufacture of the cells, the realization of the negative current collector in copper, followed by the production of the positive cathode paste. These three production chains together are claimed to make up 56$87 \%$ of the total battery impact.

Studies [16] and [31] state that, regardless of the chemistry of batteries, the energy requirements needed for production are a major cause of global warming.

There is a conflict between the results obtained from studies [16], [26] and [31] and those obtained from study [15], in which the production phase, which includes the manufacturing of the cells, generates almost completely negligible environmental impacts compared to the materials preparation phase. The difference probably derives from the database used, the 
study [26] uses the data of Ecoinvent 3.1, while the [31] of Ecoinvent 2.2, determining a quantity of greenhouse gases emitted respectively six times higher for the entire production phase and two times higher for the cells fabrication, compared to those calculated by the study [15].

However, it is possible to find a common result among those obtained by the various authors: most of the greenhouse gas emissions produced during production phase (understood separately from the material preparation process) is attributable to the manufacturing phase of the cells. In particular, according to the study [26], the energy required constitutes $51 \%$ of the total impact caused in the category of global warming, relative to the production phase. Therefore, the energy mix used during the manufacturing of the cells strongly influences the emissions produced during this phase. The influence of the energy mix in the cell manufacturing phase is addressed in articles [22] and [26], through a sensitivity analysis. Acting on the energy mix allows to reduce a part of the impact caused during the production phase, while another strategy is to use more eco-sustainable materials.

A fundamental aspect in the production phase is the specific energy of the battery, since the higher it is, the more the battery will be able to provide the vehicle with the required driving range with less weight and less consumption of materials [16], [21] and less energy for its construction and use [16].

Research is in fact engaged in the development of new technologies for the construction of batteries that have greater density and energy efficiency and that avoid in their chemistry the presence of critical materials such as nickel, cobalt, manganese, copper and, secondarily, aluminium.

The common NCA and NCM batteries offer high energy density, but they contain scarce metals such as nickel and cobalt and therefore, according to the study [16], the LFP battery would turn out to be a more eco-sustainable alternative from this point of view, in fact, being composed of iron phosphate, it does not require critical materials. Despite this, the LFP battery is not satisfactory from an energy point of view, since it is associated with a higher share of the energy for the cells manufacturing compared to the NMC and NCA batteries, bringing carbon dioxide emissions to an overall higher level [16]. However, this aspect can be solved by adopting less expensive production processes suitable for the chemistry of the battery in question and by preferring renewable sources to fossil ones.

The study [31] shows how the LFP battery brings a lower environmental impact than the $\mathrm{NMC}$ in all thirteen impact categories considered. This result was obtained using a functional unit based on the energy supplied by the battery, therefore the longer life expectancy of the LFP compared to the NMC is considered, allowing to reduce environmental loads effectively. On the opposite, the functional units expressed in terms of specific energy and mass imply a lower relative variability between the two types of batteries.

The study [20] reports a migration from the use of the LCO battery to the LMO, in order to decrease the concentration of cobalt. However, the LMO battery is more invasive in the resource depletion and human toxicity than LFP [22], despite being more profitable than the latter for a share of $12 \%$ in the climate change.

Three different innovative technologies regarding battery chemistry will be briefly presented below.

Among the most promising battery technologies for next-generation electric vehicles is the lithium-sulphur (Li-S) battery. In the study [18], this new technology is compared with the traditional NCM battery and it is stated that the lithium-sulphur battery is more sustainable. In particular, thanks to a reduction in environmental impacts for a share ranging from $9 \%$ to $90 \%$ for twelve impact categories out of thirteen, while the thinning of the ozone layer would suffer an increase of approximately $71 \%$, compared to the NCM. 
Another accumulator under research and development is the sodium-ion battery (SIB). The results obtained from the comparison between SIB and traditional LIBs show a positive attenuation of human toxicity and freshwater eutrophication thanks to the use of SIBs.

The lithium-air or lithium-oxygen $\left(\mathrm{Li}-\mathrm{O}_{2}\right)$ battery is also at the focus of attention in the development of new technologies that are sustainable for the environment. The study [17] shows how $\mathrm{Li}_{-} \mathrm{O}_{2}$ brings a greater environmental impact in the categories relating to human toxicity, terrestrial ecotoxicity and thinning of the ozone layer compared to the NCM battery. On the opposite, $\mathrm{Li}_{-} \mathrm{O}_{2}$ appears to be positive in the other eight impact categories considered, especially in eutrophication, acidification and toxicity of fresh and marine water.

Li-O $\mathrm{O}_{2}$ would be the best, among the three new technologies just presented, in terms of ecological footprint (consumption of ecological resources), carbon footprint $\left(\mathrm{CO}_{2}\right.$ equivalent emissions related to greenhouse gas emissions problems) and water footprint (consumption and pollution of water by human activities) [20].

In conclusion, it can be said that the battery production phase is very expensive, both as regards the necessary metals and for the cell manufacturing phase.

The chemistry of the cells plays a fundamental role, in particular it is necessary to consider any critical materials and the possible need for particular manufacturing processes, with consequent different electrical consumptions. It is therefore important to consider an adequate energy mix, preferring the use of renewable sources. The search for innovative and more energy efficient processes is also important.

It is important to create batteries with more eco-sustainable chemicals, also optimizing the production processes, adapting them to the type of chemistry treated. Furthermore, these innovative batteries must meet the requirements of high specific energy and high energy density, in order to reduce the amount of materials necessary for the construction of the batteries themselves and the energy required for their production, while maintaining the range required for the vehicle.

\subsection{Use Phase}

Even for LCA studies relating to the use phase of the vehicle or battery pack, the initial data and hypotheses are very important.

Between the studies of articles [11] and [29], relating to the comparison between thermal and electric vehicle, a different result in climate change can be noted.

In the study [29], the diesel-powered vehicle (ICEV) turns out to be much more polluting than the electric one (BEV), while in [11] the exact opposite happens. The quantitative results, relating to the entire life cycle, expressed in $\mathrm{Co}_{2}$-eq $\mathrm{g} / \mathrm{km}$, are shown in Fig. 4.

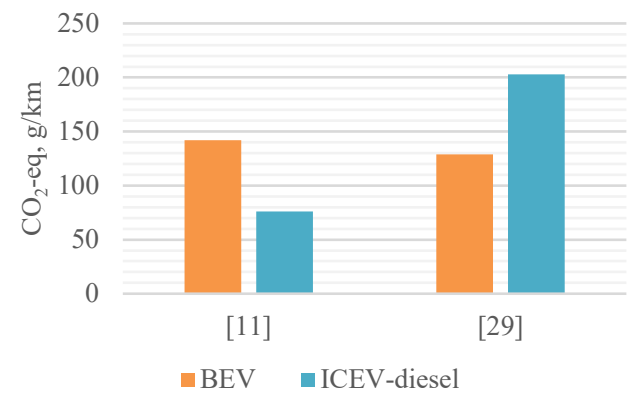

Fig. 4. LCA results relating to the impact of greenhouse gas emissions for studies [11] and [29], respectively in the years 2015 and 2017, for the entire life cycle of vehicles. 
For both studies, emissions are calculated over a distance of $150000 \mathrm{~km}$ and the use phase is the predominant source of greenhouse gas emissions.

The reason for the difference in the results obtained lies in the fact that the diesel-powered vehicle of the case [29] has a much higher consumption than that of the study [11], while for electric vehicles the opposite occurs. Furthermore, the energy mix with which the batteries of the two electric vehicles under consideration are charged also entails a substantial difference in emissions; in fact, the amount of equivalent carbon dioxide emitted during the production of electricity is greater for the Lithuanian mix than for the average European mix.

The importance of a certain energy mix for an LCA study can be considerable, both for the production phase and for the use phase.

The environmental loads associated with the energy mix used, in addition to depending on the type of sources that are used, also vary according to the time slots in which the batteries are recharged, in particular, the night one (00:00-7:00) tends to involve environmental charges lower than the daytime one (9:00-17:00) [30].

In the study [29] a break-even analysis is carried out, considering the kilometres travelled and three different energy mixes: the average European, the Norwegian one (mainly composed of renewable energies) and the Polish one (consisting almost exclusively of fossil fuels). The study showed that the energy mix of the use phase is irrelevant in modifying the environmental loads for the categories relating to human toxicity and metal depletion, in fact these two categories depend almost exclusively on the production phase.

Chemistry, in addition to influencing the impacts introduced by production, is in some cases one of the reasons for the greater dependence of some impact categories on the use phase rather than on the production phase. For example, acidification is more dependent on production for the NCM battery, for both studies [17] and [18], while the two innovative chemists treated, $\mathrm{Li}-\mathrm{O}_{2}$ and $\mathrm{Li}-\mathrm{S}$, respectively, have a large contribution given by the use phase. Furthermore, the chemistry implies a different efficiency of the batteries and their different life expectancy [31].

Another important aspect is associated with life expectancy, the kilometres travelled by the car (without replacing the battery pack), as reported in the study [29]. The greater the distance that the electric vehicle is able to travel, the greater the possibility of reducing the environmental loads introduced by production, also recovering the initial advantage of the ICEV.

The goal is therefore to have batteries with a high number of charge-discharge cycles [26]. In particular, the duration of a battery depends on its aging (increase in internal resistance and in the rate of self-discharge and reduction in capacity) and on various variables related to the use phase (intensity of current, operating and maintenance temperature, charging mode). The function of the BMS (Battery Management System) is therefore important.

It is well known that the driving cycle has a relevant impact on overall energy consumption and emissions [36].

The study [30] investigates the different outcome in terms of environmental impact associated with three different driving profiles for an LMO battery, namely aggressive $(213.4 \mathrm{Wh} / \mathrm{km})$, normal $(182.8 \mathrm{Wh} / \mathrm{km})$ and ECO $(167.1 \mathrm{Wh} / \mathrm{km})$. The latter would be able to generate a reduction in environmental impacts that is between $42 \%$ and $50 \%$ per $\mathrm{km}$ depending on the impact category considered (abiotic depletion, acidification, eutrophication and global warming), since the battery is discharged with a lower current and, therefore, the resulting losses and energy consumption are lower.

The study [26] shows how a higher efficiency level of the battery, and in general of the powertrain, is fundamental in determining a greater number of total kilometres travelled by 
the electric vehicle, with the same number of battery cycles; similarly, greater efficiency allows you to travel the same number of kilometres with fewer cycles.

In addition to the losses associated with the efficiency of the battery, there are those related to the transport of the battery itself (of its weight, in particular of the additional weight necessary to compensate for the low efficiency, to obtain the same vehicle range). This aspect is addressed by the study [27], which investigates the losses related to the weight of the battery and those associated with its internal efficiency. The latter, for an internal efficiency of $90 \%$, are always higher than those attributable to the transport of the battery.

Furthermore, it is possible to further reduce losses attributable to the weight of the battery thanks to regenerative braking [21]. However, the weight of the battery is not negligible; in fact, according to the calculations of the study, an increase in the weight-energy ratio from $15 \%$ to $50 \%$ determines an increase in the energy lost due to the three times higher weight of the battery, considering the mid-western European energy mix.

A reduction in volume is also important; in fact, in addition to implying a lower consumption of material in the production phase [37], it also involves a possible saving due to the missing fraction of vehicle destined to transport the additional volume of the battery.

Therefore, the research for ever lighter and more compact batteries must be accompanied by the need for greater efficiency (both of the battery and of the powertrain [26]) in order to obtain a reduced environmental impact, thanks to the reduction of all losses attributable to the battery.

In conclusion, to reduce the environmental loads of the use phase, it is important to use an energy mix mainly composed of renewable sources, preferring night-time charging cycles.

Furthermore, the chemistry of the cells must ensure a highly efficient and large capacity battery. The duration of the use phase must also be adequate; in this regard it is important that the vehicle control unit manages control systems aimed at reducing consumption and extending the useful life of the battery pack.

Finally, it is important to search for materials that make it possible to create ever lighter and more compact batteries.

\subsection{Recycling Phase}

Recycling is a useful methodology for recovering materials from exhaust batteries, materials that would otherwise have to be mined to produce new accumulators, resulting in the introduction of additional environmental loads.

Most of these materials are precious metals, such as nickel, lithium, cobalt and manganese, others are organic and plastic materials, which can produce large quantities of pollutants in the production and extraction phases [15], [26]; some are highly toxic and dangerous if not disposed of properly, such as PVDF binder, as it releases hydrofluoric acid when burned, or flammable mixtures used in the electrolyte formation, such as those composed of ethylene carbonate and dimethyl carbonate [19]. For these reasons, appropriate end-of-life treatment practices are needed.

The study [23] shows that, for lithium-ion batteries, the Eco-indicator points deriving from the weighting process of the results obtained in the categories of damage related to human health, ecosystem quality and resource depletion, beyond under 200 cycles of battery chargedischarge, decrease as the recycling percentage increases and, markedly, when the latter reaches at least $40-50 \%$.

A simple disposal does not allow to obtain the benefits that would derive instead from a correct recycling practice, as demonstrated by the study [24]. According to the latter, recycling would lead to a reduction in ecological points by a share of $23 \%$. 
Recycling practices also require energy and material input to the system itself, with the consequent introduction of environmental loads which are, however, generally low compared with those that compete in the production and use phases [11], [16]-[18], [29].

There are different technologies used for recycling, the more classic ones involve methods of chemical extraction of metals and they are pyrometallurgical and hydrometallurgical treatments [38]. The first uses high temperatures to obtain the constituent elements of the cathode, allowing the recovery of aluminium, copper, cobalt, nickel, manganese and titanium; while the second uses an acid or alkaline solution through which salts of lithium, cobalt, nickel, manganese, magnesium and titanium are obtained [16], [25].

The pyrometallurgical treatment, if compared with the hydrometallurgical one, offers significantly lower advantages, above all due to the greater consumption of electricity required for the treatment [15], since it is carried out at a high temperature, and the loss of lithium in the waste [16]. According to the study [25], pyrometallurgical treatment appears to be the methodology to which the least environmental benefits are attributed for LMO, NCM and NCA batteries with regard to climate change, as affirmed in the study [16] for NCA, NCM, SIB and LFP batteries; in particular, the latter sees an increase with respect to the environmental impacts generated in production. Also with regard to the depletion of abiotic resources, pyrometallurgical process is the one that brings the least benefits, with the exception of the sodium ion battery, which with this treatment obtains greater advantages compared to the hydrometallurgical one.

However, hydrometallurgical recycling requires a large amount of water (water requirement problem). Nonetheless, hydrometallurgical process implies lower environmental loads than pyrometallurgic one, which is connected to higher emissions of atmospheric pollutants and greenhouse gases, due to the production and combustion of carbon coke during the process; this combustion is responsible for the releases of sulphur dioxide, with consequent damage to human health if they are not treated properly (using a washing system based on calcareous sulphur) [29].

In general, a pyrometallurgical or hydrometallurgical treatment does not allow the LFP and SIB batteries to considerably reduce the environmental impacts generated during the production phase, as is the case for NCM and NCA batteries. This depends on the materials recovered.

The evolution towards innovative chemicals, which allow a reduction in the percentages of heavy and critical metals, must therefore be accompanied by a continuous research for suitable recycling processes.

The study [15] shows that, for the NCM battery, the hydrometallurgical treatment brings significant advantages in all impact categories considered. In particular, the best results are associated with the impact categories relating to the production of photochemical oxidants and human toxicity, with a reduction of $105.2 \%$ and $139.8 \%$ respectively, thanks to the large amount of recovered aluminium, which is the most responsible for the impacts caused in these two categories.

The study [22] analyses the hydrometallurgical treatment for LMO and LFP batteries, which is the standard one for these batteries. In this case, the hydrometallurgical treatment allows greater savings in electricity consumption, compared to the pyrometallurgical one [39].

The effectiveness of recycling treatments largely depends on the chemistry of the battery in question, therefore, for innovative chemicals, treatments designed specifically are required.

An innovative method is direct recycling, which is a non-destructive technique that allows the recovery of the cathode and electrolyte. It therefore allows the direct reuse of the material after preliminary light processing, if necessary [25], [38]. In fact, the recovered materials are 
not always used in the production of batteries for the automotive sector. Many studies report the benefits associated with the second use of batteries in other areas.

The study [25] certifies the effectiveness of cascade use, i.e., the efficient use of resources using residues and recycled materials, for the analysed NCM, NCA and LMO batteries. In particular, the application in stationary energy storage systems would allow the reduction of environmental loads related to the life cycle of the batteries used during their first life in the automotive sector.

The study [25] states that direct cathode recycling is associated with lower environmental loads than those of hydrometallurgical and pyrometallurgical treatments, also with regard to global warming [25], [40]. Furthermore, it would be able to guarantee a lower amount of waste from the recycling process [39] and it would be able to offer a high contribution in effectively reducing the impact generated in production phase of the batteries with low-cost chemicals such as LFP [16].

In general, the greatest benefit obtainable from recycling is the reduction of the metals used for the production of new batteries [16], [22] and the lowering of the emissions related to the extraction and processing of the metals themselves.

However, the greenhouse gas emissions released during the cell manufacturing cannot be significantly reduced by recycling due to the high energy consumption required for this phase.

An important aspect is the efficiency of recycling, which determines the effectiveness or otherwise of the treatment and the quality of the recycled product.

We must also pay attention to the economic aspect, the recovery of metals of low monetary value through recycling could introduce greater economic burdens than environmental benefits.

Further attention should be paid to transport, which is necessary to bring exhausted batteries to recovery centers; in this phase, the generation of significant environmental loads must be avoided [39].

In conclusion, recycling treatments need to be refined according to the chemistry in question, so that they are also suitable for innovative chemicals.

\section{Discussion ANd CONCLUSION}

Thanks to this literature review it was possible to show how different aspects and parameters influence the results of LCA studies applied to electric vehicles and, in particular, to their battery pack.

The absence of unified and/or accessible data regarding battery design [26] and manufacturing processes can lead to significant differences between LCA inventories and, therefore, between the results obtained.

The functional unit adopted, defining the study approach, also leads to different results. For example, analysing batteries with a functional unit based on their mass does not allow to fully consider the efficiency during the use phase [31] and the specific energy level [35]. The latter is the reason why NCM and NCA batteries have significantly lower environmental performance than LFPs when the functional unit is expressed in terms of mass, while when this is based on energy, the opposite result is obtained [35].

From the studies analysed, the battery production phase was often dominant in the life cycle. This is mainly related to the materials used and to the manufacturing of the cells, especially the energy required for this process. In this regard it is necessary to pay particular attention to the type of battery in question; in fact, a different chemistry involves different processes, materials and quantities of energy. 
Having ascertained that metals such as nickel, cobalt, manganese, copper and, secondarily, aluminium are particularly critical, some from the point of view of toxicity, others from that of resource depletion and/or greenhouse gas emissions, it is useful to evolve towards products greener chemicals.

A help to reduce environmental impacts comes from the use of energy from renewable sources, which has lower environmental loads than that from fossil sources. The energy mix influences both the manufacturing and use phases. It is therefore also useful to pay attention to the daily hours in which the battery is recharged.

To promote the growth of renewable energies, innovative and flexible electricity distribution network systems, called 'SmartGrid', are indispensable, together with storage systems, with the aim of solving the problem linked to uncertainty, discontinuity and nonprogrammability of renewable sources.

Another important aspect to consider is that of the specific energy of the battery. In fact, a high specific energy, for the same vehicle range, allows the use of lower quantities of materials and energy for manufacturing and it allows the reduction of losses associated with the transport of the battery itself.

Important to reduce environmental loads are also high battery durability and high efficiency of the battery pack (and, in general, of the vehicle), together with the ecological use of the car, obtainable thanks to the development of control strategies, managed by a control unit, and thanks to the will of the driver.

Recycling makes it possible to reduce some of the impacts introduced with the production phase, those relating to the materials and processes required, but not those strictly related to the use of energy for manufacturing. The research for new efficient recycling strategies must go hand in hand with the research for innovative and less impactful materials from an environmental point of view.

In addition to the environmental aspect, the economic aspect should also be considered: capital and maintenance costs associated with infrastructures suitable for the circulation of the growing number of electric vehicles, the purchasing power of people, and the different costs of the different battery chemistries and so on.

Finally, the transition to electric mobility would cause a non-negligible social impact: transition from petrol station to electric charging stations, from the thermal engine to the electric one, from mechanical to electrical connections, etc.

Therefore, many aspects should be taken into consideration in the transition towards electric mobility, since this has not only an environmental impact, but also social and economic ones. These last two aspects are beyond the aim of this article, but to properly assess the sustainability of electric mobility they should not be overlooked.

\section{ACKNOWLEDGEMENT}

Special thanks go to ENEA (Italian National Agency for New Technologies, Energy and Sustainable Economic Development) for supporting the research.

\section{REFERENCES}

[1] Arshad F., et al. A Comprehensive Review of the Advancement in Recycling the Anode and Electrolyte from Spent Lithium Ion Batteries. ACS Sustainable Chemistry and Engineering 2020:8(36):13527-13554 https://doi.org/10.1021/acssuschemeng.0c04940

[2] Chindamo D., et al. Simulation tool for optimization and performance prediction of a generic hybrid electric series powertrain. International Journal of Automotive Technology 2014:15:135-144. https://doi.org/10.1007/s12239-014$\underline{0015-9}$ 
[3] Zhang R., et al. State of the art of lithium-ion battery SOC estimation for electrical vehicles. Energies 2018:11(7):1820. https://doi.org/10.3390/en11071820

[4] Casals L. C., Amante García B., Canal C. Second life batteries lifespan: Rest of useful life and environmental analysis. Journal of Environmental Management 2019:232:354-363. https://doi.org/10.1016/j.jenvman.2018.11.046

[5] European Environment Agency. Electric vehicles from life cycle and circular economy perspectives. TERM 2018: Transport and Environment Reporting Mechanism (TERM) report. EEA Report. No 13/2018. ISSN 1977-8449. Copenhagen: EEA, 2018.

[6] Ehsani M., et al. Modern Electric, Hybrid Electric, and Fuel Cell Vehicles. 3rd ed. Boca Raton: CRC Press, Taylor \& Francis Group, 2008.

[7] Attualità Parlamento europeo. Emissioni di $\mathrm{CO}_{2}$ delle auto: i numeri e i dati. Infografica. (News European Parliament. $\mathrm{CO}_{2}$ emissions from cars: numbers and data. Infographic.) [Online]. [Accessed 02.02.2021]. Available: https:/www.europarl.europa.eu/news/it/headlines/society/20190313STO31218/emissioni-di-co2-delle-auto-i-numerie-i-dati-infografica (in Italian)

[8] European Council, Council of the European Union. Stricter $\mathrm{CO}_{2}$ Emission Standards for Cars and Vans Signed Off by the Council [Online]. [Accessed 09.12.2020]. Available: https:/www.consilium.europa.eu/en/press/pressreleases/2019/04/15/stricter-co2-emissionstandards-for-cars-and-vans-signed-off-by-the-council/

[9] Regulation of the European Parliament and of the council setting $\mathrm{CO}_{2}$ emission performance standards for new passenger cars and for new light commercial vehicles, and repealing Regulations (EC) No 443/2009 and (EU) No $510 / 2011$ (recast). Brussels: The European Parliament, 2019.

[10] Attualità Parlamento europeo. Auto e inquinamento: i nuovi obiettivi (News European Parliament. Cars and pollution: the new goals) [Online]. [Accessed 04.02 .2021$]$ Available: https://www.europarl.europa.eu/news/it/headlines/society/20180920STO14027/auto-e-inquinamento-i-nuoviobiettivi-per-le-emissioni (in Italian)

[11] Petrauskienė K., Skvarnavičiūtė M., Dvarionienė J. Comparative environmental life cycle assessment of electric and conventional vehicles in Lithuania. Journal of Cleaner Production 2020:246:119042. https://doi.org/10.1016/j.jclepro.2019.119042

[12] European Environmental Agency. Number of Europeans exposed to harmful noise pollution expected to increase. [Online]. [Accessed 20.02.2021]. Available: https://www.eea.europa.eu/highlights/number-of-europeans-exposed-to

[13] Cecchel S. et al. Lightweighting in automotive: cradle-to-grave life cycle assessment of a safety relevant component. International Journal of Life Cycle Assessment 2018:23(10):2043-2054. https://doi.org/10.1007/s11367-017-1433-5

[14] Jolliet O., et al. Environmental Life Cycle Assessment. Boca Raton CRC Press, 2015.

[15] Sun X., et al. Life cycle assessment of lithium nickel cobalt manganese oxide (NCM) batteries for electric passenger vehicles. Journal of Cleaner Production 2020:273:123006. https://doi.org/10.1016/j.jclepro.2020.123006

[16] Mohr M., et al. Toward a cell-chemistry specific life cycle assessment of lithium-ion battery recycling processes. Journal of Industrial Ecology 2020:24(6):1310-1322. https://doi.org/10.1111/jiec.13021

[17] Wang F., Deng Y., Yuan C. Life cycle assessment of lithium oxygen battery for electric vehicles. Journal of Cleaner Production 2020:264:121339. https://doi.org/10.1016/j.jclepro.2020.121339

[18] Deng Y., et al. Life cycle assessment of lithium sulfur battery for electric vehicles. Journal of Power Sources 2017:343:284-295. https://doi.org/10.1016/j.jpowsour.2017.01.036

[19] Peters J., et al. Life cycle assessment of sodium-ion batteries. Energy and Environmental Science 2016:9(5):17441751. https://doi.org/10.1039/C6EE00640J

[20] Wang L., et al. Lithium-air, lithium-sulfur, and sodium-ion, which secondary battery category is more environmentally friendly and promising based on footprint family indicators? Journal of Cleaner Production 2020:276:124244. https://doi.org/10.1016/j.jclepro.2020.124244

[21] Peters J. F., Weil M. A critical assessment of the resource depletion potential of current and future lithium-ion batteries. Resources 2016:5(4):46. https://doi.org/10.3390/resources5040046

[22] Oliveira L., et al. Key issues of lithium-ion batteries - from resource depletion to environmental performance indicators. Journal of Cleaner Production 2015:108(PA):354-362. https://doi.org/10.1016/j.jclepro.2015.06.021

[23] Yu Y., et al. Environmental impact assessment and end-of-life treatment policy analysis for Li-ion batteries and NiMH batteries. International Journal of Environmental Research and Public Health 2014:11(3):3185-3198. https://doi.org/10.3390/ijerph110303185

[24] Unterreiner L., Jülch V., Reith S. Recycling of Battery Technologies - Ecological Impact Analysis Using Life Cycle Assessment (LCA). Energy Procedia 2016:99:229-234. https://doi.org/10.1016/j.egypro.2016.10.113

[25] Tao Y., You F. Comparative life cycle assessment of three recycling approaches for electric vehicle lithium-ion battery after cascaded use. Chemical Engineering Transactions 2020:81:1123-1128. https://doi.org/10.3303/CET2081188

[26] Ellingsen L. A.-W., et al. Life Cycle Assessment of a Lithium-Ion Battery Vehicle Pack. Journal of Industrial Ecology 2014:18(1):113-124. https://doi.org/10.1111/jiec.12072

[27] Zackrisson M., Avellán L., Orlenius J. Life cycle assessment of lithium-ion batteries for plug-in hybrid electric vehicles -Critical issues. Journal of Cleaner Production 2010:18(15):1519-1529. https://doi.org/10.1016/j.jclepro.2010.06.004

[28] Burchart-Korol D., et al. Life cycle impact assessment of electric vehicle battery charging in European Union countries. Journal of Cleaner Production 2020:257:120476. https://doi.org/10.1016/j.jclepro.2020.120476 
[29] Pero F. D., Delogu M., Pierini M. Life Cycle Assessment in the automotive sector: A comparative case study of Internal Combustion Engine (ICE) and electric car. Procedia Structural Integrity 2018:12:521-537. https://doi.org/10.1016/j.prostr.2018.11.066

[30] Faria R., et al. Primary and secondary use of electric mobility batteries from a life cycle perspective. Journal of Power Sources 2014:262:169-177. https://doi.org/10.1016/j.jpowsour.2014.03.092

[31] Majeau-Bettez G., Hawkins T. R., StrØmman A. H. Life cycle environmental assessment of lithium-ion and nickel metal hydride batteries for plug-in hybrid and battery electric vehicles. Environmental Science and Technology 2011:45(10):4548-4554. https://doi.org/10.1021/es103607c

[32] Badino V., Baldo G. L. LCA: istruzioni per l'uso (LCA: instructions for use). Progetto Leonardo, 1998. (in Italian)

[33] Alliance, Effective and affordable automobile lightweighting [Online]. [Accessed 22.02.2021]. Available: http://lightweight-alliance.eu/project/

[34] Blagoeva D., et al. Assessment of potential bottlenecks along the materials supply chain for the future deployment of low-carbon energy and transport technologies in the EU. Wind power, photovoltaic and electric vehicles technologies, time frame 2015 - 2030. Luxembourg: Publications Office of the European Union, 2016. https://doi.org/10.2790/08169

[35] Dolganova I., et al. A review of life cycle assessment studies of electric vehicles with a focus on resource use. Resources 2020:9(3):32. https://doi.org/10.3390/resources9030032

[36] Chindamo, D., Gadola, M. What is the Most Representative Standard Driving Cycle to Estimate Diesel Emissions of a Light Commercial Vehicle? IFAC-PapersOnLine 2018:51(5):73-78. https://doi.org/10.1016/j.ifacol.2018.06.213

[37] Patry G., et al. Cost modeling of lithium-ion battery cells for automotive applications. Energy Science and Engineering 2015:3(1):71-82. https://doi.org/10.1002/ese3.47

[38] Nordelöf A., et al. Methodological approaches to end-of-life modelling in life cycle assessments of lithium-ion batteries. Batteries 2019:5(3):51. https://doi.org/10.3390/batteries5030051

[39] Hendrickson T. P., et al. Life-cycle implications and supply chain logistics of electric vehicle battery recycling in California. Environmental Research Letters 2015:10(1):014011. https://doi.org/10.1088/1748-9326/10/1/014011

[40] Ciez R. E., Whitacre J. F. Examining different recycling processes for lithium-ion batteries. Nature Sustainability 2019:2(2):148-156. https://doi.org/10.1038/s41893-019-0222-5 